\title{
Left ventricular relaxation at rest and during handgrip in aortic valve disease before and after valve replacement*
}

\author{
W. Deuel, O. M. Hess, M. Turina, Å Senning and H. P. Krayenbuehl \\ Medical Policlinic, Cardiology, and Surgical Clinic A, University Hospital, Zurich, Switzerland
}

KEY WORDS: Relaxation, time constant of pressure fall, handgrip, aortic valve disease, aortic valve replacement

In 14 patients (pts) with aortic valve disease (AVD) left ventricular ( $L V$ ) relaxation was assessed by the time constant ( $T$ ) of $L V$ pressure (tipmanometer) fall before and 19 months after successful aortic valve replacement $(A V R)$. 12 control pts $(C O)$ were studied by the same technique. Preoperative LV ejection fraction in $A V D(64 \%)$ and in $C O(69 \%)$ did not differ. In AVD T was increased (60 ms) as compared to the $C O(38 \mathrm{~ms}, P<0.05)$. During handgrip $(H G)$ there was a similar increase of $L V$ peak systolic pressure (LVSP), heart rate and peak measured contractile element velocity of shortening in $A V D$ and in the $C O$. LV end-diastolic pressure varied minimally in both groups. $T$ decreased during handgrip in $C O$ ( 38 to $33 \mathrm{~ms}, P<0.01)$ and remained unchanged in $A V D$. Following $A V R T$ at rest decreased insignificantly to $52 \mathrm{~ms}$, but remained increased $(P<0.025)$ as compared with $C O$. During postoperative $H G$ however, a decrease to $47 \mathrm{~ms}(P<0.05)$ was noted. Postoperative angiographic $L \mathrm{~V}$ muscle mass $\left(105 \mathrm{~g} / \mathrm{m}^{2}\right)$ and $L V S P$ at rest $(137 \mathrm{mmHg})$ remained elevated $(P<0.02)$ as compared to $C O\left(72 \mathrm{~g} / \mathrm{m}^{2} ; 119 \mathrm{mmHg}\right)$. It is concluded that (l) in $A V D$ with normal ejection performance $L V$ relaxation at rest is prolonged and the reaction of relaxation to $H G$ is abnormal despite preserved contractile response, (2) following $A V R$ the response of $L V$ relaxation to $H G$ becomes normal and (3) elevated postoperative $T$ at rest appears to be related to residual hypertrophy and probably also to the still increased LVSP rather than to intrinsic disturbances of myocardial relaxation.

In patients with secondary hypertrophy consequent to aortic valve disease, left ventricular (LV) relaxation as evaluated by the time constant (T) of LV pressure decay has been shown to be impaired[1]. T was particularly prolonged in the patients with severe LV angiographic hypertrophy.

Although LV peak systolic pressure was originally thought not to influence $T^{[2]}$ Gaasch and coworkers ${ }^{[3]}$ have noted recently in open chest dogs that $T$ increased significantly when peak systolic pressure was augmented suddenly by cross clamping the ascending aorta during diastole. Hence the augmentation of LV peak systolic pressure per se

Received for publication 25 March 1982; and in revised form 16 August 1982

*Supported by a grant of the Swiss National Science Foundation

Correspondence in $\mathrm{H}$ P Krayenbuehl. MD. Medical Policlinic. Cardiology University Hospital CH-8091 Zurich must also be considered as a possible cause for the increased $T$ in aortic valve disease. Because the absolute values of $T$ appear then to be inconclusive for evaluating intrinsic LV relaxation in aortic valve disease we anticipated that the reaction of $T$ to an increase in afterload produced by isometric exercise (handgrip) and its comparison to the response in normal controls might be helpful for further characterizing LV relaxation in these patients.

In the present study it is shown that prior to surgery this reaction is abnormal and becomes normal after successful aortic valve replacement.

\section{Materials and Methods}

Fourteen patients with aortic valve disease (4 with aortic stenosis, 5 with combined lesion, 5 with aortic insufficiency) underwent diagnostic right and 
left heart catheterization and LV cineangiography which was biplane in most instances. Coronary artery disease was excluded in 11 of them by selective arteriography. In three patients, all below the age of 30 , coronary arteriography was not carried out. Following the diagnostic part of the catheterization but before any angiographic procedure a micromanometer tipped catheter was inserted into the left ventricle $\left.{ }^{4}\right]$. First a control pressure run was recorded. Then the patient carried out a standardized handgrip test by squeezing a balloon dynamometer with a strength of $30 \%$ of maximal voluntary contraction[s]. At the end of the third minute a second pressure run was obtained. Twelve control patients who were catheterized because of atypical chest pain or a systolic murmur underwent the same test. Calibrated LV angiograms were available in eight of the control patients.

From the LV high-fidelity pressure (P) curves peak measured velocity of contractile element shortening $(\mathrm{Vpm})$ was determined as reported previously ${ }^{[45]}$. As a measure of $L V$ relaxation $T$ was obtained from the slope of the linear regression analysis of $\mathrm{P}$ and negative $\mathrm{dP} / \mathrm{dt}[1,6,7]$. For this calculation coordinates of $\mathrm{P}$ and negative $\mathrm{dP} / \mathrm{dt}$ were used starting at or a few ms after peak negative $\mathrm{dP} / \mathrm{dt}$ and ending when the $\mathrm{LV}$ pressure decline had reached the level of end-diastolic pressure. $\mathrm{LV}$ volumes were determined according to the area-length technique. LV muscle mass was calculated according to the method of Rackley and co-workers ${ }^{[8]}$.

The statistical comparisons were carried out with the paired or unpaired Student $t$-test as appropriate. For the comparison of correlation coefficients of linear regression analyses ( $P$ vs negative $\mathrm{dP} / \mathrm{dt}$ ) the Wilcoxon rank-sum test for paired or unpaired differences was used.

Nineteen (11-25) months after successful aortic valve replacement with a Björk-Shiley prosthesis in 6 and a bioprosthesis in 8 instances the 14 patients were recatheterized and the handgrip test was repeated in the same manner as preoperatively. All the patients had been asked by letter for their consent to undergo the second catheterization. In no instance were there clinical or angiographic signs of aortic leakage at the time of reinvestigation.

\section{Results}

The data (mean values \pm 1 standard deviation) at rest and during handgrip are summarized in Table 1. The patients with aortic valve disease (AVD) were significantly older than the control subjects. LV end-diastolic volume and muscle mass were significantly increased as compared with the controls. LV ejection fraction did however not differ between the two groups.

During handgrip heart rate and LV peak systolic pressure increased significantly in both controls and the patients with AVD. There was no significant difference in the extent of increase (Fig. 1). LV end-diastolic pressure did not change and $\mathrm{Vpm}$ increased significantly in both groups during handgrip. Again the magnitude of the changes was similar (Fig. 2) although the patients with AVD started from a significantly lower $\mathrm{Vpm}$ than the controls. A major factor for the diminished $\mathrm{Vpm}$ at rest in these patients with AVD and normal ejection performance appeared to be the increased LV enddiastolic pressure which by itself, and unrelated to contractile abnormalities, tends to depress $\mathrm{Vpm}[9,10]$.

The regression analyses between $P$ and negative $\mathrm{dP} / \mathrm{dt}$ carried out for the determination of $\mathrm{T}$ showed no ideal straight line which would indicate a true exponential decay of pressure but the slope of $P$ vs negative $\mathrm{dP} / \mathrm{dt}$ was, especially in the patients with AVD, slightly biphasic with a flatter portion immediately after peak negative $\mathrm{dP} / \mathrm{dt}$ and a steeper portion at the lower negative $\mathrm{dP} / \mathrm{dt}$ values ${ }^{[1]}$. Nevertheless the correlation coefficients ( $r$ ) of the regression analyses were high indicating that the deviation from a true exponential pressure decay was small. In the controls $r$ was $0.989 \pm 0.012$ at rest and $0.986 \pm 0.012$ during handgrip. This difference was not significant. In the patients with AVD, $r$ at rest $(0.971 \pm 0.030)$ was slightly but not significantly smaller than in the controls. During handgrip $r$ $(0.964 \pm 0.042)$ did not change. In the patients with AVD following surgery $r$ at rest was $0.981 \pm$ 0.012 and did not change during handgrip $(0.977 \pm 0.017)$.

Although it is recognized that the LV pressure decay is not truly exponential, $\mathrm{T}$, as calculated in the above mentioned manner, was considered a useful measure for characterizing $L V$ relaxation. At rest, $T$ was significantly prolonged in the patients with AVD; during handgrip, $T$ decreased significantly in the controls and remained unchanged in AVD. Figs. 3 and 4 show typical examples of the behaviour of $T$ in a control subject and in a patient with aortic stenosis, respectively. In Fig. 5 all individual values of $\mathrm{T}$ at rest and during handgrip are plotted.

After aortic valve replacement LV end-diastolic 
Table I Hemodynamic data at rest (R) and during handgrip (HG) in the control subjects and in the patients with aortic valve disease before (AVD pre-op) and after successful aortic valve replacement ( $A V D$ post-op)

\begin{tabular}{|c|c|c|c|c|c|c|c|c|c|c|c|c|}
\hline & \multirow{2}{*}{$\begin{array}{l}\text { Age } \\
\text { (yrs) }\end{array}$} & \multirow{2}{*}{ EDVI } & \multirow{2}{*}{$\mathrm{EF}$} & \multirow{2}{*}{ LMMI } & \multicolumn{2}{|c|}{$\underbrace{H R}$} & \multicolumn{2}{|c|}{ LVSP } & \multicolumn{2}{|c|}{ LVEDP } & $\underbrace{V p}_{p m}$ & $\mathrm{~T}$ \\
\hline & & & & & R & $\mathrm{HG}$ & R & $\mathrm{HG}$ & R & $\mathrm{HG}^{\prime}$ & $\mathrm{HG}$ & $\mathrm{HG}$ \\
\hline $\begin{array}{l}\text { A. Controls }(n=12) \\
P\end{array}$ & $32 \pm 12$ & $76 \pm 16$ & $69 \pm 6$ & $72 \pm 13$ & $\begin{array}{r}75 \pm 13 \\
<0\end{array}$ & $001 \pm 13$ & $\begin{array}{r}119 \pm 10 \\
<0\end{array}$ & $143 \pm 16$ & $9 \pm 1$ & $S^{8 \pm 2}$ & $\begin{array}{c}1.72 \pm 0.26 \quad 1.97 \pm 0.25 \\
<0.001\end{array}$ & $\underset{<0.01}{38 \pm 12} 33 \pm 14$ \\
\hline $\begin{array}{l}\text { B AVD pre-op }(n=14) \\
P\end{array}$ & $44 \pm 12$ & $157 \pm 56$ & $64 \pm 7$ & $156 \pm 41$ & $\begin{array}{r}70 \pm 6 \\
<0 .\end{array}$ & $\begin{array}{l}84 \pm 7 \\
001\end{array}$ & $\begin{array}{r}183 \pm 45 \\
<0\end{array}$ & $\begin{array}{l}210 \pm 43 \\
001\end{array}$ & ${ }^{18 \pm 10}$ & $S^{20 \pm 11}$ & $\begin{array}{c}1.21 \pm 0.33 \quad 1.41 \pm 0.32 \\
<0.005\end{array}$ & 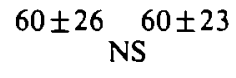 \\
\hline $\begin{array}{l}\text { C. AVD post-op }(n=14) \\
P\end{array}$ & $46 \pm 12$ & $100 \pm 17$ & $66 \pm 9$ & $105 \pm 34$ & $\begin{array}{r}73 \pm 10 \\
<0\end{array}$ & $84 \pm 11$ & $\begin{aligned} 137 \pm 22 & <0\end{aligned}$ & $\begin{array}{l}169 \pm 29 \\
.001\end{array}$ & ${ }^{10 \pm 5}<0$ & $.02 \pm 5$ & $\begin{array}{c}1.39 \pm 0.28 \quad 1.61 \pm 0.34 \\
<0.005\end{array}$ & $\begin{array}{c}52 \pm 13 \quad 47 \pm 16 \\
<0.05\end{array}$ \\
\hline $\begin{array}{l}P_{\mathrm{A} \text { vs } \mathrm{B}} \\
P_{\mathrm{B}} \text { vs } \mathrm{C} \\
P_{\mathrm{A}} \text { vs } \mathrm{C}\end{array}$ & $\begin{array}{l}<0.02 \\
<0.01\end{array}$ & $\begin{array}{l}<0.001 \\
<0.001 \\
<0.005\end{array}$ & $\begin{array}{l}\text { NS } \\
\text { NS } \\
\text { NS }\end{array}$ & $\begin{array}{l}<0.001 \\
<0.001 \\
<0.02\end{array}$ & $\begin{array}{l}\text { NS } \\
\text { NS } \\
\text { NS }\end{array}$ & $\begin{array}{l}\text { NS } \\
\text { NS } \\
\text { NS }\end{array}$ & $\begin{array}{l}<0.001 \\
<0.001 \\
<0.02\end{array}$ & $\begin{array}{l}<0.001 \\
<0.001 \\
<0.02\end{array}$ & $\begin{array}{l}<0.005 \\
<0 \cdot 005 \\
\quad \text { NS }\end{array}$ & $\begin{array}{l}<0.005 \\
<0.002 \\
<0.05\end{array}$ & $\begin{array}{l}<0.001 \\
\text { NS } \\
<0.01\end{array}$ & $\begin{array}{cc}<0.05 & <0.005 \\
\text { NS } & <0.05 \\
<0.025 & <0.05\end{array}$ \\
\hline
\end{tabular}

EDVI = left ventricular end-diastolic volume $\left(\mathrm{ml} / \mathrm{m}^{2}\right) ; E F=$ left ventricular ejection fraction $(\%) ; \mathrm{LMMI}=$ left ventricular muscle mass $\left(\mathrm{g} / \mathrm{m}^{2}\right) ; \mathrm{HR}=$ hear rate $(\mathrm{bpm}) ;$ $\mathrm{LVSP}=$ left ventricular peak systolic pressure $(\mathrm{mmHg}) ; \mathrm{LVEDP}=$ left ventricular end-diastolic pressure $(\mathrm{mmHg}) ; \mathrm{Vpm}=$ peak measured velocity of contractile element shortening (muscle lengths/s); $\mathrm{T}=$ time constant of pressure decay (ms) $P=$ probability; NS $=$ not significant $(P>0.05)$. Data are mean values $\pm I$ standard deviation. EDVI and LMMI were determined in only $8 / 12$ control subjects. 

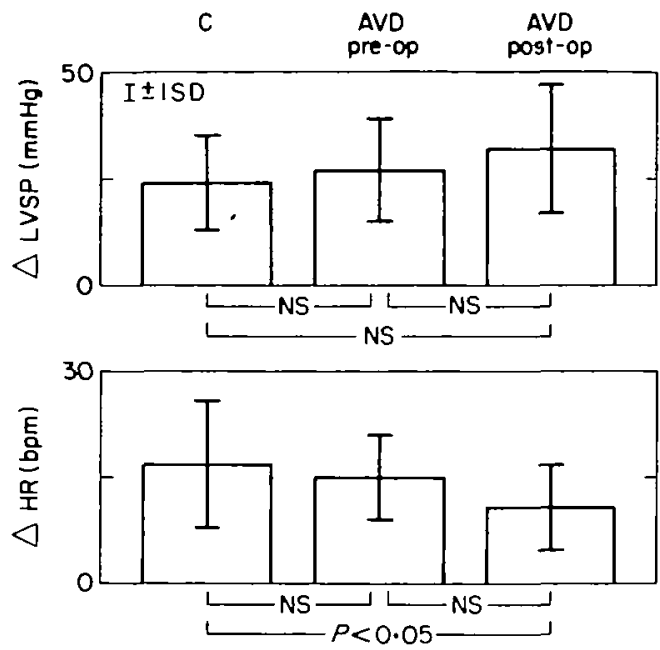

Figure 1 Increase in left ventricular peak systolic pressure (LVSP) and heart rate (HR) during handgrip in the controls $(C)$ and in the patients with aortic valve disease (AVD) before (pre-op) and after aortic valve replacement (post-op). The increase in LVSP did not differ among the three groups, whereas the increase in heart rate was slightly smaller in AVD post-op than in the C. $(P=$ probability, $\mathrm{NS}=$ not significant $(\mathrm{P}>0.05), \mathrm{SD}=$ standard deviation).
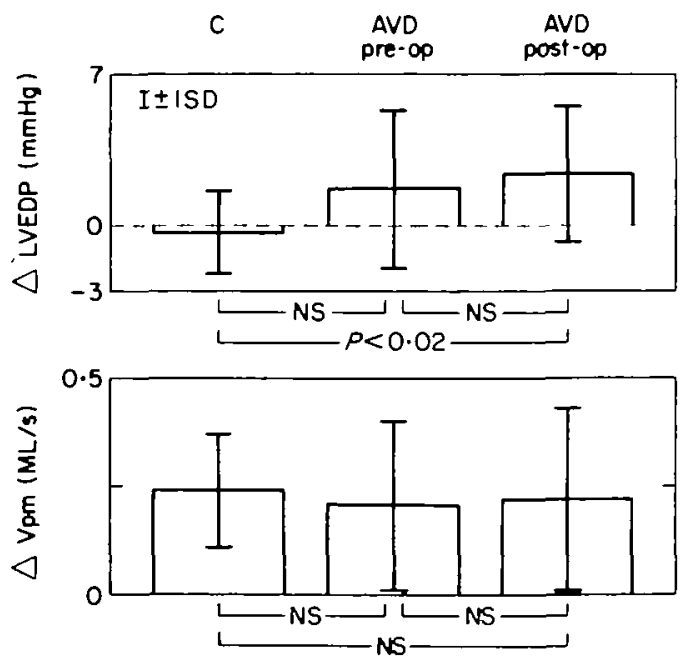

Figure 2. Changes in left ventricular end-diastolic pressure (LVEDP) and peak measured contractile element velocity of shortening (Vpm) in the controls (C) and in the patients with aortic valve disease (AVD) before and after valve replacement. There was a similar increase of $\mathrm{Vpm}$ in the three groups. Whereas in the C LVEDP did not change, there was a minor increase of LVEDP in AVD before and after surgery. The later one was significant as compared to $\mathrm{C}$. (ML=muscle lengths; other abbreviations see Fig. 1.) volume, muscle mass and peak systolic pressure decreased significantly although they remained elevated as compared with the controls. The LV ejection fraction did not change. LV end-diastolic pressure decreased and accordingly $\mathrm{Vpm}$ increased. $T$ decreased slightly and insignificantly from 60 to $52 \mathrm{~ms}$. During handgrip, which was carried out at the same strength and duration as preoperatively, heart rate increased somewhat less than at the preoperative investigation and in the controls (Fig. 1). This smaller increase in heart rate was accompanied by a slightly more marked change of the LV end-diastolic pressure (Fig. 2) the extent of which $(+2.4 \mathrm{mmHg})$ remained, however, within the limits of normality as defined previously[s]. There was no difference in change of LV peak systolic pressure and $\mathrm{Vpm}$ as compared to the preoperative handgrip and the handgrip in the controls. Unlike preoperatively $T$ decreased significantly during handgrip after surgery (Fig. 5). This reaction of $T$ was similar to that observed in the control subjects. Fig. 6 shows the reaction of $T$ during postoperative handgrip in the same patient, whose preoperative handgrip was depicted in Fig. 4.

Because the postoperatively still increased LV peak systolic pressure may have prolonged $T$ at rest, those patients $(n=8)$ with aortic valve replacement who had a LV peak systolic pressure below the individual maximal LVSP of $138 \mathrm{mmHg}$ observed in the group of controls were evaluated separately. In these 8 patients, LVSP at rest averaged $121 \pm 10 \mathrm{mmHg}$ and did not differ from LVSP in the controls $(119 \pm 10 \mathrm{mmHg})$. $\mathrm{T}$ at rest was $54 \pm 12 \mathrm{~ms}$ and was longer $(P<0.05)$ than $\mathrm{T}$ in the controls (38 \pm 12 ). During handgrip, $T$ decreased from $54 \pm 12$ to $46 \pm 14 \mathrm{~ms}(P<0.05)$ in this subset of 8 patients with aortic valve replacement. Angiographic muscle mass of the subset was $104 \pm$ $35 \mathrm{~g} / \mathrm{m}^{2}(P<0.05$ as compared with rontrols).

\section{Discussion}

The time constant of isovolumic pressure decay (T) is a generally accepted measure of LV relaxation[6.7.11]. In patients with secondary hypertrophy from aortic valve disease, $T$ has been found to be prolonged[']. The nature of this prolongation is however not clearly evident because depression of intrinsic myocardial contractility $[2,6,12]$, advanced hypertrophy[1] and elevation of LV peak systolic pressure ${ }^{[3]}$ may each lead to increased $T$. To gain further insight into the mechanisms involved with the prolongation of $T$ in patients with aortic valve 

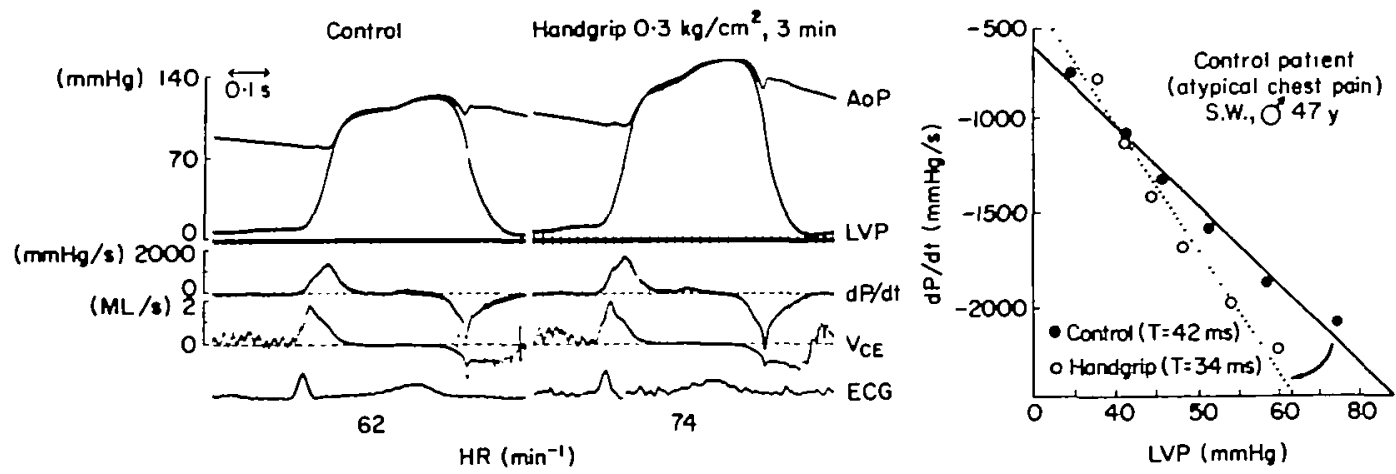

Figure 3 Left ventricular and aortic high-fidelity pressure curves (on the left) and negative $\mathrm{dP} / \mathrm{dt}$-left ventricular pressure relation (on the right) before and during handgnp in a 47-year old patient with atypical chest pain (control subject). There was an increase of left ventricular peak systolic pressure, peak positive $\mathrm{dP} / \mathrm{dt}$ and peak measured $\mathrm{V}_{\mathrm{CE}}$. The relation between negative $\mathrm{dP} / \mathrm{dt}$ and left ventricular pressure during relaxation became steeper during handgrip and accordingly $T$ decreased. Abbreviations: AoP $=$ aortic pressure, LVP =left ventricular pressure, $\mathrm{dP} / \mathrm{dt}=$ first derivative of left ventricular pressure, $\mathrm{V}_{\mathrm{CE}}=$ instantanteous velocity of shortening of the contractile elements, $\mathrm{HR}=$ heart rate, $\mathrm{ECG}=$ electrocardiogram, $\mathrm{T}=$ time constant of left ventricular pressure fall.
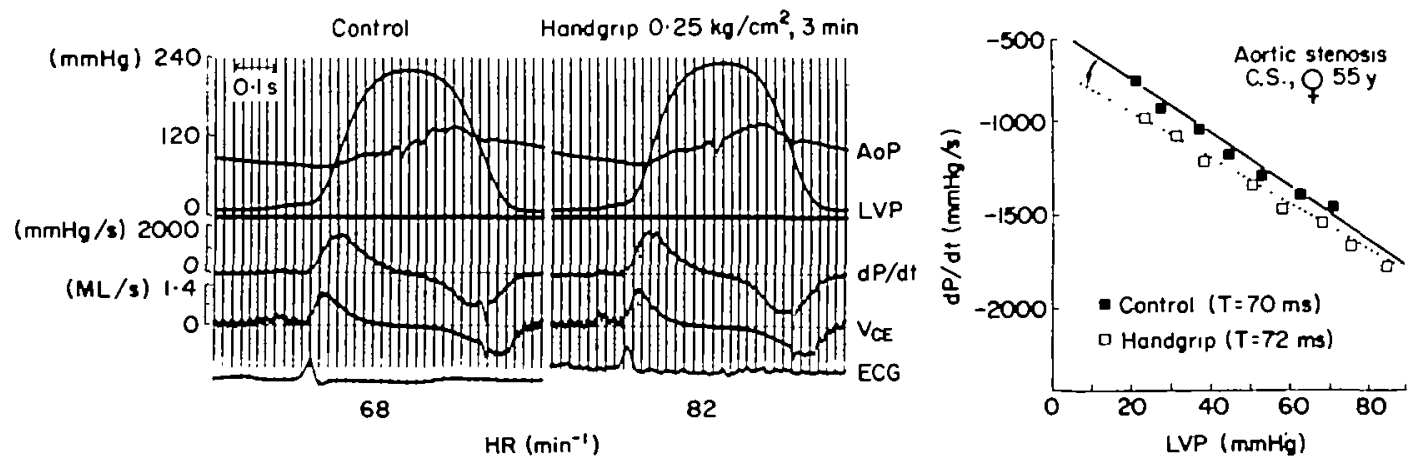

Figure 4: Left ventricular and aortic high-fidelity pressure curves (on the left) and negative dP/dt-left ventricular pressure relation (on the right) before and during handgrip in a 55-year old patient with aortic stenosis. During handgrip there was an increase of left ventricular peak systolic pressure, peak positive $\mathrm{dP} / \mathrm{dt}$ and peak measured $\mathrm{V}_{\mathrm{CE}}$. The relation between negative $\mathrm{dP} / \mathrm{dt}$ and $\mathrm{LVP}$, and accordingly $\mathrm{T}$, remained essentially unchanged during handgrip. (For abbreviations see Fig. 3.)

disease, we studied $L V$ relaxation during isometric stress and compared this response with the reaction of $\mathrm{T}$ observed in control subjects.

In patients with normal LV function, handgrip leads to an increase of contractile indexes with little or no change in end-diastolic pressure ${ }^{[5.13]}$. This type of reaction was observed in our control patients as well as in the patients with aortic valve disease (Fig. 2). Moreover LV ejection fraction was not different in the patients with aortic valve disease and the controls (Table I). Hence LV systolic contractile function appeared to be well preserved despite the chronic abnormal loading conditions.
Although LV systolic function was normal in these patients with aortic valve disease, the response of $\mathrm{T}$ during handgrip was different from that in the controls. Whereas in the controls $T$ decreased significantly during isometric exercise (because the effect of the increase in contractility in shortening $T$ had probably overridden the effect in prolonging $T$ of the increase of peak systolic pressure occurring with handgrip) $T$ remained unchanged in the patients with aortic valve disease. Thus, an intrinsic abnormality of relaxation became apparent which otherwise would have been difficult to define because the prolongation of $T$ at rest in aortic valve 

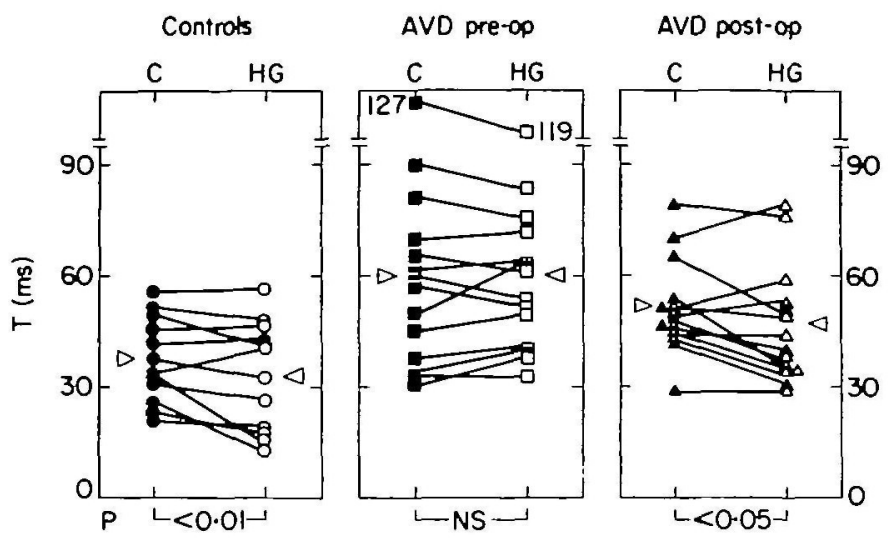

Figure 5 Time constant of left ventricular pressure fall $(\mathrm{T})$ before $(\mathrm{C})$ and during handgrip (HG) in the controls and in the patients with aortic valve disease (AVD) before (pre-op) and after (post-op) aortic valve replacement.

In the controls $\mathrm{T}$ decreased significantly, whereas it remained unchanged in the patients with AVD prior to surgery. After aortic valve replacement $T$ decreased significantly, similarly to the controls. (The triangles indicate mean values. $\mathrm{P}=$ probability, $\mathrm{NS}=$ not significant.)
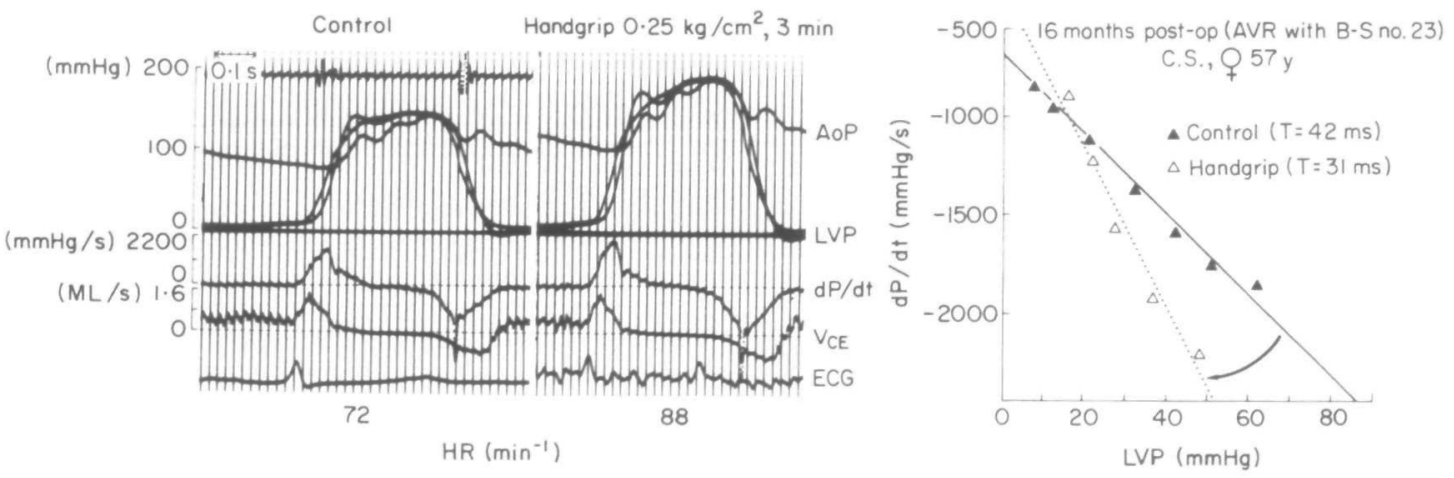

Figure 6. Left ventricular high-fidelity and conventional and aortic conventional pressure curves (on the left) and negative $\mathrm{dP} / \mathrm{dt}$-left ventricular pressure relation (on the right) before and during handgrip following valve replacement in the same patient as depicted in Fig. 4. Again handgrip led to an increase of left ventricular peak systolic pressure, peak positive $\mathrm{dP} / \mathrm{dt}$ and peak measured $\mathrm{V}_{\mathrm{CE}}$. In contrast to the preoperative test, the negative $\mathrm{dP} / \mathrm{dt}-\mathrm{LVP}$ relation became sizably steeper during handgrip and accordingly $T$ decreased. (Abbreviations: $A V R=$ aortic valve replacement, B-S=Björk-Shiley; other abbreviations as in Fig. 4.)

disease could be explained by the increased peak systolic pressure and angiographic mass. Since the failure to shorten $T$ occurred in the presence of unaltered systolic reaction, it is suggested that for the early detection of subtle abnormalities of the inotropic state of the myocardium, relaxation parameters may be more sensitive than measures of systolic function. Similar conclusions have been reached by others, based upon the noninvasive determination of a prolonged isovolumic relaxation time in patients with primary and secondary hypertrophy[14.15].

Following successful aortic valve replacement $T$ at rest decreased insignificantly from 60 to $52 \mathrm{~ms}$. During handgrip, however, $T$ decreased significantly to $47 \mathrm{~ms}$ (Table I, Fig. 5). This reaction was similar to that observed in the controls. Hence, after valve replacement, there was normalization of the 
response of relaxation during handgrip. Thus even in patients with normal preoperative systolic function, where beneficial effects of valve replacement on myocardial function are difficult to substantiate, a definite functional improvement could be demonstrated.

At rest, $T$ remained elevated in the patients with aortic valve replacement as compared with the controls. This prolongation appeared to be related predominantly to the residual LV hypertrophy because in a subset of 8 postoperative patients with normal LV peak systolic pressure at rest angiographic muscle mass was still increased as compared with the controls. It can however not be excluded that the increased LV peak systolic pressure in the remaining 6 postoperative patients contributed in prolonging $\mathrm{T}$.

In conclusion, it can be stated that in patients with aortic valve disease and normal ejection performance, $\mathrm{LV}$ relaxation as evaluated by $\mathrm{T}$ is prolonged at rest and the response of relaxation to isometric exercise is abnormal despite preserved systolic contractile response. This abnormal response to handgrip suggests the presence of true intrinsic disturbances of relaxation not evident from the prolongation of $\mathrm{T}$ at rest, because the elevation of LV peak systolic pressure and ventricular hypertrophy per se may cause an increase of $\mathrm{T}$. Following aortic valve replacement the response of $T$ to handgrip becomes normal, indicating reversibility of the intrinsic disturbances of relaxation.

The authors are indebted to Mrs R. Rindlisbacher for careful secretarial work.

\section{References}

[1] Eichhorn P, Grimm J, Koch R, Hess O, Carroll J, Krayenbuehl HP. Left ventricular relaxation in patients with left ventricular hypertrophy secondary to aortic valve disease. Circulation 1982; 65: 1395-404.

[2] Frederiksen JW, Weiss JL, Weisfeldt ML. Time constant of isovolumic pressure fall: determinants in the working left ventricle. Am J Physiol 1978; 235: H $701-6$.
[3] Gaasch WH, Blaustein A, Andrias CW, Donahue RP, Avitall B. Myocardial relaxation. II. Hemodynamic determinants of the rate of left ventricular isovolumetric pressure decline. Am J Physiol 1980; ; 39: H1-6.

[4] Krayenbuehl HP, Rutishauser W, Wirz P, Amende I, Mehmel $H$. High-fidelity left ventricular pressure measurements for the assessment of cardiac contractility in man. Am J Cardiol 1973; 31: 415-27.

[5] Krayenbuehl HP, Rutishauser W, Schoenbeck M, Amende I. Evaluation of left ventricular function from isovolumic pressure measurements during isometric exercise. Am J Cardiol 1972; 29: 323-30.

[6] Weisfeldt ML, Weiss JL, Frederiksen JT, Yin FCP. Quantification of incomplete left ventricular relaxation: relationship to the time constant of isovolumic pressure fall. Eur Heart J 1980; I, Suppl A: 119-29.

[7] Raff GL, Glantz SA. Volume loading slows left ventricular isovolumic relaxation rate. Evidence of loaddependent relaxation in the intact dog heart. Circ Res 1981; 48: 813-24.

[8] Rackley CE, Dodge HT, Coble YD Jr, Hay RE. A method for determining left ventricular mass in man. Circulation 1964; 29: 666-71.

[9] Kreulen TH, Bove AA, McDonough MT, Sands MJ, Spann JF. The evaluation of left ventricular function in man: A comparison of methods. Circulation 1975; 51: 677-88.

[10] Gunther S, Grossman W. Determinants of ventricular function in pressure-overload hypertrophy in man. Circulation 1979; 59:679-88.

[11] Mann T, Goldberg S, Mudge GH Jr, Grossman W. Factors contributing to altered left ventricular diastolic properties during angina pectoris. Circulation 1979; 59: 14-20.

[12] Karliner JS, LeWinter MM, Mahler F, Engler R, O'Rourke RA. Pharmacologic and hemodynamic influences on the rate of isovolumic left ventricular relaxation in the normal conscious dog. J. Clin Invest 1977; 60: 511-21.

[13] Quinones MA, Gaasch WH, Waisser W, Thiel HG, Alexander JK. An analysis of the left ventrncular response to isometric exercise. Am Heart J 1974; 88: 29-36.

[14] Hanrath P: Mathey DG, Siegert R, Bleifeld W. Left ventricular relaxation and filling pattern in different forms of left ventricular hypertrophy: An echocardiographic study. Am J Cardiol 1980; 45: 15-23.

[15] Gibson DG, Traill TA, Hall RJC, Brown DJ. Echocardiographic features of secondary left ventricular hypertrophy. Br Heart J 1979; 41: 54-9. 